\title{
The Therapeutic Mode of Action of 4-Aminopyridine in Cerebellar Ataxia
}

\author{
Karina Alviña and Kamran Khodakhah \\ Dominick P. Purpura Department of Neuroscience, Albert Einstein College of Medicine, Bronx, New York 10461
}

Episodic ataxia type 2 (EA2) is a hereditary cerebellar ataxia associated with mutations in the $\mathrm{P} / \mathrm{Q}$-type voltage-gated calcium $\left(\mathrm{Ca}^{2+}\right)$ channels. Therapeutic approaches for treatment of EA2 are very limited. Presently, the potassium $\left(\mathrm{K}^{+}\right)$channel blocker 4-aminopyridine (4-AP) constitutes the most promising treatment, although its mechanism of action is not understood. Here we show that, in contrast to what is commonly believed, therapeutic concentrations of 4-AP do not increase the inhibitory drive of cerebellar Purkinje cells. Instead, 4-AP restores the severely diminished precision of pacemaking in Purkinje cells of EA2 mutant mice by prolonging the action potential and increasing the action potential afterhyperpolarization. Consistent with this mode of action, the therapeutic efficacy of 4-AP was comparable, and not additive, to chlorzoxazone, an activator of $\mathrm{Ca}^{2+}$-dependent $\mathrm{K}^{+}$channels that also restores the precision of Purkinje cell pacemaking. The likely target of 4 -AP at the concentrations used are the $\mathrm{K}_{\mathrm{v}} 1$ family of $\mathrm{K}^{+}$channels, possibly the $\mathrm{K}_{\mathrm{v}} 1.5$ subtype. Because at higher concentrations 4-AP blocks a large array of $\mathrm{K}^{+}$channels and is a proconvulsant, use of selective $\mathrm{K}_{\mathrm{v}} 1$ channel blockers is likely to be a safer substitute for treatment of cerebellar ataxia.

\section{Introduction}

Episodic ataxia type 2 (EA2) is a form of hereditary neurological disorder caused by cerebellar malfunction and is characterized by interictal ataxia and frequent attacks of dyskinesia, vertigo, and imbalance that last for hours to days (Jen et al., 2007). EA2 is associated with mutations in the $\mathrm{Ca}_{\mathrm{v}} 2.1 \alpha 1$ pore-forming subunit of the P/Q-type voltage-gated calcium $\left(\mathrm{Ca}^{2+}\right)$ channel, which reduce its current density (Fletcher et al., 1996; Ophoff et al., 1996; Dove et al., 1998). These channels are widely expressed in the CNS and are particularly enriched at synaptic nerve terminals (Stea et al., 1994) and in cerebellar Purkinje cells (Mori et al., 1991; Usowicz et al., 1992).

Current treatments for EA2 are limited (Jen et al., 2007; Strupp et al., 2007). Recently, the potassium $\left(\mathrm{K}^{+}\right)$channel blocker 4-aminopyridine (4-AP) was used for treatment of this disorder (Strupp and Brandt, 2006; Strupp et al., 2008) in humans and also in animal models of EA2 such as the tottering $(\mathrm{tg} / \mathrm{tg})$ mouse (Weisz et al., 2005). The mode of action of 4-AP is not understood. 4-AP has been prescribed based on the assumption that, because of the reduced P/Q-type $\mathrm{Ca}^{2+}$ current density, the Purkinje cell inhibitory drive to neurons of deep cerebellar nuclei (DCN) is reduced (Glasauer et al., 2005; Kalla et al., 2007; Strupp et al., 2008). Because in Purkinje cells 4-AP decreases the latency of $\mathrm{Ca}^{2+}$ spikes evoked with large depolarizing pulses

Received July 23, 2009; revised March 17, 2010; accepted April 8, 2010.

This work was supported by the National Institutes of Health. Studies on the effects of 4-AP on Purkinje cells were initiated by Dr. Simin Khavandgar during her tenure in K.K.'s lab. We are particularly grateful to her, and also thank members of K.K.'s lab for help in scoring the motor behavior of the mice and for discussions.

Correspondence should be addressed to Kamran Khodakhah, Dominick P. Purpura Department of Neuroscience, Albert Einstein College of Medicine, Kennedy Center, Room 506, 1410 Pelham Parkway South, Bronx, New York 10461. E-mail:k.khodakhah@einstein.yu.edu.

DOI:10.1523/JNEUROSCI.3582-09.2010

Copyright $\odot 2010$ the authors $\quad 0270-6474 / 10 / 307258-11 \$ 15.00 / 0$
(Etzion and Grossman, 2001), it was thought that 4-AP would restore their inhibitory drive onto DCN neurons (Strupp and Brandt, 2006; Jen et al., 2007; Strupp et al., 2007, 2008). However, several recent findings are inconsistent with these assumptions. Unlike that postulated, the firing rates of mutant Purkinje cells in animal models of EA2 are not lower (Hoebeek et al., 2008; Ovsepian and Friel, 2008). Moreover, despite the presence of morphological synaptic abnormalities, stimulation of Purkinje cells inhibits DCN neurons of $\mathrm{tg} / \mathrm{tg}$ mice with the same efficacy (mean latency and pause duration) as it does in the wild type (wt) (Hoebeek et al., 2008).

Because as a $\mathrm{K}^{+}$channel blocker 4-AP is a relatively potent proconvulsant (Bever et al., 1994; Judge et al., 2006), understanding its mode of action is necessary if we are to supersede it by offering safer alternatives. We thus sought to delineate the therapeutic mode of action of 4-AP. We found that at therapeutic concentrations 4-AP neither increased the firing rate nor excitability of Purkinje cells or synaptic drive to DCN neurons. Instead, 4-AP effectively restored the precision of pacemaking in the mutant $\mathrm{tg} / \mathrm{tg}$ Purkinje cells by increasing the duration of action potentials and the amplitude of afterhyperpolarizations (AHPs). 4-AP's efficacy in restoring the precision of Purkinje cell pacemaking was mimicked by selective blockade of $\mathrm{K}_{\mathrm{v}} 1.5$ channels. Consistent with a mode of action on Purkinje cell pacemaking, the therapeutic benefits of $4-\mathrm{AP}$ in the $\mathrm{tg} / \mathrm{tg}$ mice were not additive to those of chlorzoxazone $(\mathrm{CHZ})$, which also restores the precision of Purkinje cell pacemaking.

\section{Materials and Methods}

Cerebellar slices. All procedures employed were in accordance with the policies established by the Animal Institute Committee of the Albert Einstein College of Medicine.

Postnatal day 12 (P12)-P19 Wistar rats and 2- to 3-month-old $\operatorname{tg} / \mathrm{tg}$ or age-matched C56BL/6 mice were (wt) anesthetized with halothane and 
decapitated. The brains were quickly removed and placed in cold extracellular solution containing the following (in $\mathrm{mm}$ ): $125 \mathrm{NaCl}, 2.5 \mathrm{KCl}, 26$ $\mathrm{NaHCO}_{3}, 1.25 \mathrm{NaH}_{2} \mathrm{PO}_{4}, 1 \mathrm{MgCl}_{2}, 2 \mathrm{CaCl}_{2}$, and 10 glucose, $\mathrm{pH} 7.4$ when gassed with $5 \% \mathrm{CO}_{2} / 95 \% \mathrm{O}_{2}$. The cerebellums were dissected and mounted on a modified Oxford vibratome and 300- $\mu$ m-thick sagittal slices were made. The slices were kept in oxygenated extracellular solution at $34^{\circ} \mathrm{C}$ for $1 \mathrm{~h}$, and then at room temperature until use $(1-5 \mathrm{~h})$.

Extracellular recordings. Slices were placed in a recording chamber on the stage of a Zeiss Axioskop microscope. Purkinje cells were visually identified using a $40 \times$ water-immersion objective with infrared optics. The slices were superfused with the extracellular recording solution at a rate of $1.5-2 \mathrm{ml} / \mathrm{min}$ and the temperature adjusted to $35 \pm 1{ }^{\circ} \mathrm{C}$. Extracellular recordings were obtained from single neurons using a homemade differential amplifier and glass pipette electrodes filled with extracellular solution (tip size, $0.3-1 \mu \mathrm{m}$ ). The pipette tip was positioned just above, or lightly touching, the cell body near the axon hillock where the largest potential changes were usually recorded. To isolate the Purkinje cell intrinsic activity, synaptic transmission was blocked using $5 \mathrm{~mm}$ kynurenic acid (Spectrum Chemical MFG), a broad-spectrum ionotropic glutamate receptor antagonist (Stone, 1993); $100 \mu \mathrm{M}$ picrotoxin (Sigma), a $\mathrm{GABA}_{\mathrm{A}}$ receptor antagonist (Yoon et al., 1993); and $1 \mu \mathrm{M}$ CGP55845 [(2S)-3-[[(1S)-1-(3,4-dichlorophenyl)ethyl] amino-2hydroxypropyl] (phenylmethyl) phosphinic acid; Tocris Bioscience], a $\mathrm{GABA}_{\mathrm{B}}$ receptor antagonist (Davies et al., 1993). These antagonists were present in all experiments except in those which examined synaptic transmission. 4-AP was obtained from Sigma.

Data were sampled at $10 \mathrm{kHz}$ using an analog-to-digital converter (PCI-MIO-16XE-10; National Instruments), and acquired and analyzed using custom software written in LabView (National Instruments).

In each experiment, interspike interval histograms were constructed using a long stretch of spontaneous activity ( $>5 \mathrm{~min}$ ). These histograms were used to calculate the predominant (instantaneous) firing rate, defined as the reciprocal of the interspike interval most frequently observed (the peak of the histogram, i.e., its mode), and the maximum (instantaneous) firing rate, defined as the reciprocal of the shortest interspike interval which accounted for at least $5 \%$ of interspike intervals (Womack and Khodakhah, 2003).

Whole-cell recordings. Whole-cell voltage-clamp recordings were performed using an Optopatch amplifier (Cairn Research) with electrodes pulled from borosilicate glass ( $1-3 \mathrm{M} \Omega$ resistance when filled with intracellular solution). The intracellular solution used was composed of the following (in mM): 70 Cs-gluconate, $10 \mathrm{CsF}, 20 \mathrm{CsCl}, 10 \mathrm{EGTA}, 10$ HEPES, and $3 \mathrm{Na}_{2} \mathrm{ATP}, \mathrm{pH} 7.4(\mathrm{CsOH})$. Recordings obtained from deep cerebellar neurons were performed using a high-chloride intracellular solution containing the following (in mM): $138 \mathrm{CsCl}, 10 \mathrm{CsF}, 10 \mathrm{HEPES}$, $5 \mathrm{NaCl}$, and $3 \mathrm{MgATP}$, pH $7.2(\mathrm{CsOH})$. For whole-cell current-clamp recordings, the intracellular solution contained the following (in $\mathrm{mM}$ ): $140 \mathrm{~K}$-methyl sulfate, $10 \mathrm{KCl}, 5 \mathrm{NaCl}, 4 \mathrm{MgATP}, 0.01 \mathrm{EGTA}$, and 10 HEPES, pH $7.33(\mathrm{KOH})$.

Data were sampled at $20 \mathrm{kHz}$ using an analog-to-digital converter (PCI-MIO-16XE-10; National Instruments), and acquired and analyzed using a custom software written in LabView (National Instruments).

Electrical stimulation. Parallel fibers (PFs) were electrically stimulated by a glass pipette (filled with extracellular solution) placed in the molecular layer, above the Purkinje cell under study. In every trial, a single 100 $\mu$ s current pulse (2-20 $\mu \mathrm{A}$ intensity) was delivered using a constant current isolated stimulator (DS3; Digitimer LTD). To measure the paired-pulse ratio, two identical electric pulses were delivered separated by a 50 -ms-long interval. To stimulate mossy fibers, the stimulation pipette was placed in the white matter tract underneath the granule cell layer that targeted the Purkinje cell under study.

To stimulate Purkinje cells inputs to DCN neurons, the stimulation pipette was positioned between the cerebellar cortex and the nuclei to prevent direct effects on nuclear cells.

Behavioral analysis. We used the accelerating rotarod test as a paradigm to examine motor performance (Walter et al., 2006; Crawley, 2008). The apparatus consisted of a 3-cm-diameter rotating rod (Rotamex-5; Columbus Instruments) elevated $55 \mathrm{~cm}$ above a covered platform. Each trial started from stationary position accelerating at a rate of
$0.1 \mathrm{~cm} / \mathrm{s}$ every second. The animals' speed and latency to fall were automatically recorded by an interfaced computer. Every day, $\mathrm{tg} / \mathrm{tg}$ mice and wt littermates (4-5 months old) were tested in 10 consecutive trials.

To quantify the frequency, severity, and duration of episodes of dyskinesia observed in $t g / t g$ mice, the overall motor behavior was scored every $10 \mathrm{~min}$ before and after each rotarod session for up to $2 \mathrm{~h}$. The scoring followed a scale published previously (Weisz et al., 2005) as follows: 0 , normal motor behavior; 1 , slightly slowed or abnormal movements; 2, mild impairments, limited ambulation unless disturbed; 3, moderate impairment, limited ambulation even when disturbed, frequent abnormal postures; 4 , severe impairment, almost no ambulation, sustained abnormal postures; 5, prolonged immobility in abnormal postures.

The stress and exertion associated with the rotarod trials resulted in long-lasting episodes of paroxysmal dyskinesia. The severe attacks (scores of 4-5) typically last for 30-60 min and are very stereotyped. These attacks start with the involuntary extension of hind limbs followed by lowering of the hips and extending the knees, ankles, and paws. Throughout these movements, the back is abnormally arched. This posturing then spreads to the rest of the body, with particularly severe contractions of the neck and face muscles (Campbell et al., 1999). Most of these characteristics are notable every time a $\mathrm{tg} / \mathrm{tg}$ mouse has a severe attack, making the severe episodes (scores of 4-5) unambiguously distinguishable from milder motor impairments (scores of 2-3).

Scoring of the severity of the symptoms was performed by one of the authors with previous knowledge of the treatment implemented. To ascertain that this scoring was not biased, a few colleagues who were blind to the treatment were also asked to provide dyskinesia scores by reviewing a number of videotaped episodes. There were no significant differences between the scores assigned by five such observers blind to the treatment of the mice and the scores obtained by the authors.

$\mathrm{CHZ}$ and 4-AP were orally administered to $\mathrm{tg} / \mathrm{tg}$ and wt mice by adding them to their drinking water. The $\mathrm{CHZ}$ solution was prepared fresh every day by adding $\mathrm{CHZ}$ to a $0.1 \%$ solution of hydroxypropyl- $\beta$-cyclodextrin (Tocris Bioscience) and then adding a few drops of $1 \mathrm{~N} \mathrm{NaOH}$ until the $\mathrm{CHZ}$ was fully dissolved. The solution was supplemented with $10 \%$ sucrose to improve its taste and thus ensure its consumption. The 4-AP solution was also prepared daily from a $10 \times$ frozen stock. To improve the accuracy of the water consumption measurements, the large water bottles in the cages were replaced with graduated $15 \mathrm{ml}$ plastic tubes. The weight of the animals and the extent of their water intake were monitored daily throughout the experiment.

All data are reported as mean \pm SEM. To determine statistical significance, one-way ANOVA was followed by Bonferroni's post test for multiple comparisons or a paired $t$ test (for Fig. $2 H$ only). Differences were considered to be statistically significant only at $p<0.05$.

\section{Results}

\section{Therapeutic concentrations of 4-AP do not alter the rate of} spontaneous activity of cerebellar Purkinje cells

Although the output of Purkinje cells onto DCN neurons is dynamically regulated by their synaptic inputs, Purkinje cells are intrinsically active and fire regularly in the absence of any synaptic input (Hausser and Clark, 1997; Raman and Bean, 1999; Womack and Khodakhah, 2002). Therapeutic concentrations of 4-AP may thus increase the inhibitory synaptic drive of Purkinje cells onto DCN neurons by elevating the rate of their intrinsic pacemaking. In humans, 4-AP has a relatively short half life of 3-4 h (Hayes et al., 2003), and its beneficial effects in alleviating motor symptoms in EA2 and cerebellar and ocular motor disorders have been obtained within an hour of administration of a single $10 \mathrm{mg}$ dose, or with $5 \mathrm{mg}$ doses given thrice daily (Strupp et al., 2004; Kalla et al., 2007). Given its pharmacokinetics in humans, the maximum plasma concentration of 4-AP after a single $10 \mathrm{mg}$ dose corresponds approximately to a concentration just shy of $1 \mu \mathrm{M}$. Although throughout this study we explored the effects of 1,5 , and $10 \mu \mathrm{M} 4$-AP to more clearly delineate trends in 
A

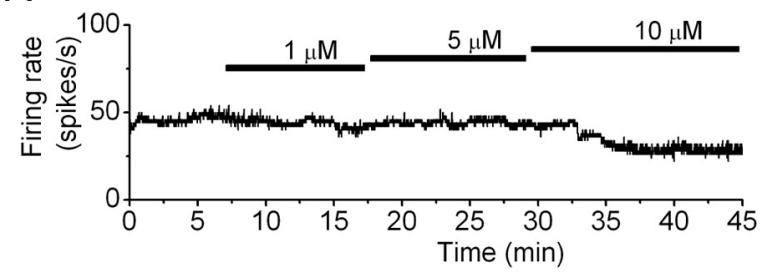

B

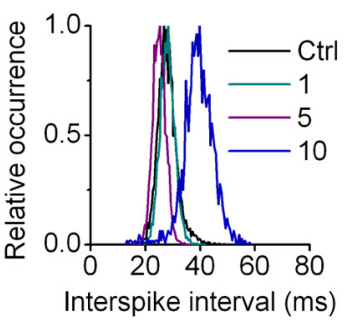

$\mathrm{C}$

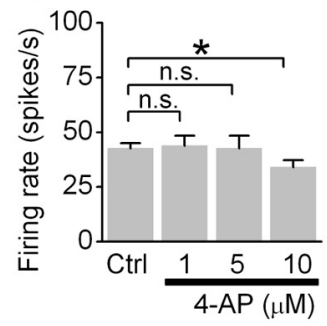

Synaptic transmission blocked
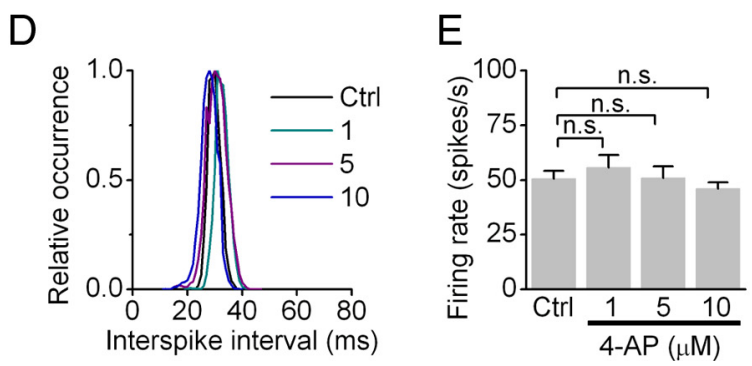

Figure 1. Therapeutic concentrations of 4-AP do not affect the activity in Purkinje cells. $A$, The firing rate of a cerebellar Purkinje cells was monitored by extracellular recording and sequentially higher concentrations of 4-AP were bath applied. $\boldsymbol{B}$, Histograms of the interspike interval distributions obtained from the cell shown in $\boldsymbol{A}$ in each condition. $\boldsymbol{C}$, Average Purkinje cell firing rates in control condition and in the presence of 4-AP. ${ }^{*} p<0.05$. D, Distribution of interspike intervals from a Purkinje cell recorded in the presence of blockers of excitatory and inhibitory synaptic transmission under control conditions and when the cell was exposed to 4-AP. E, Average Purkinje cell firing rates in control condition and in the presence of 4-AP with synaptic transmission blocked. n.s., Not significant.

potential physiologic effects, it should be noted that, therapeutically, only the $1 \mu \mathrm{M}$ concentration is of relevance particularly since higher doses are proconvulsant (Bever et al., 1994).

To explore whether therapeutic concentrations of 4-AP affect the rate of spontaneous activity of Purkinje cells, we noninvasively monitored their activity with extracellular recordings in acutely prepared cerebellar slices. After recording the activity of individual Purkinje cells for several minutes to obtain their baseline firing rate, we applied 4-AP. Bath perfusion of neither 1 nor $5 \mu \mathrm{M} 4$-AP affected the rate of spontaneous activity of Purkinje cells (control firing rate, $42.6 \pm 2.4$ spikes per second; $1 \mu \mathrm{M} 4$-AP, $43.8 \pm 4.5$ spikes per second, $p>0.1 ; 5 \mu \mathrm{M} 4-\mathrm{AP}, 42.6 \pm 5.8$ spikes per second, $p>0.1 ; n=13$ cells) (Fig. $1 A-C$ ). 4 -AP at 10 $\mu \mathrm{M}$ marginally reduced the firing rate $(33.9 \pm 3.2$ spikes per second; $p<0.05$ ), presumably by increasing GABAergic drive onto Purkinje cells, because 4-AP did not affect the firing rate of Purkinje cells when synaptic transmission was pharmacologically blocked (Fig. 1D,F). Comparable results were obtained when GABAergic synaptic transmission was selectively blocked (data not shown). Thus, the data demonstrate that therapeutic concentrations of 4-AP do not affect intrinsic pacemaking of Purkinje cells. By inference, given that at these concentrations 4-AP did not reduce the firing rate of Purkinje cells in experiments where inhibitory synaptic transmission was intact, it is likely that 4-AP also does not appreciably change the firing rate of the molecular layer interneurons.

\section{Therapeutic concentrations of 4-AP do not increase release probability at parallel fiber synapses or affect the response of Purkinje cells to synaptic input}

We next examined whether therapeutic concentrations of 4-AP potentiate the response of Purkinje cells to excitatory synaptic inputs. Purkinje cells receive excitatory inputs from $>150,000 \mathrm{PF}$ synapses. In principle, 4-AP can potentiate PF-evoked responses in Purkinje cells by increasing either the presynaptic or postsynaptic excitability (or both). At some synapses, even low micromolar concentrations of 4-AP can increase neurotransmitter release by broadening the action potential, thus leading to greater $\mathrm{Ca}^{2+}$ influx (Sacco and Tempia, 2002). 4-AP can also increase the response of a Purkinje cell to the same synaptic input if it blocks dendritic or perhaps even somatic $\mathrm{K}^{+}$channels. We explored these possibilities by first quantifying the response of spontaneously firing Purkinje cells to extracellular electrical stimulation of PFs. The intensity of the electrical stimulation was adjusted such that the maximum firing rate of the target Purkinje cells increased to about 100 spikes per second (mean, $113.4 \pm 9.1$ spikes per second; $n=8$ cells). 4 -AP, in a concentration-dependent manner, potentiated these responses (Fig. $2 A, B$ ) such that PF-evoked responses marginally increased to $129.1 \pm 16.4$ spikes per second in the presence of $1 \mu \mathrm{M} 4-\mathrm{AP}(p>0.1)$, to $174.6 \pm 28.8$ spikes per second with $5 \mu \mathrm{M} 4-\mathrm{AP}(p<0.05)$, and to $228.6 \pm 37.7$ spikes per second with $10 \mu \mathrm{M} 4-\mathrm{AP}(p<0.001)$.

To delineate the mechanism by which 4-AP potentiates PFevoked responses in Purkinje cells, we examined its effect on PF-evoked EPSCs in voltage-clamped Purkinje cells. Use of a Cs-based internal solution to block $\mathrm{K}^{+}$channels ensured a better space clamp and eliminated the possibility of a postsynaptic action of 4-AP. Similar to that seen with PF-evoked increases in the firing rate of Purkinje cells, 4-AP potentiated PF-evoked EPSCs in a concentration-dependent manner (Fig. $2 C, D)(n=12$ cells). The average peak amplitude of EPSCs was $318 \pm 24 \mathrm{pA}$ under control conditions. With $1 \mu \mathrm{M} 4$-AP it increased to $399 \pm 46 \mathrm{pA}$, although this value was not statistically different from control $(p>0.1)$. The average EPSC amplitude increased further to $473 \pm 59$ pA with $5 \mu \mathrm{M}(p<0.05)$, and to $614 \pm 59 \mathrm{pA}$ with 10 $\mu \mathrm{M} 4$-AP $(p<0.001)$. Moreover, the extent to which 4-AP augmented PF-evoked EPSCs was the same as its potentiating effects on PF-evoked increases in the firing rate (Fig. 2E). Because in Purkinje cells the increase in the firing rate is a linear function of the charge injected by the PF-evoked EPSCs (Walter and Khodakhah, 2006), our data demonstrate that therapeutic concentrations of 4-AP do not affect integration of synaptic inputs by Purkinje cells by altering their dendritic or somatic excitability. Instead, the effects of low concentrations of 4-AP are solely restricted to increasing the amplitude of EPSCs.

In the experiments reported above, a number of PFs were activated by a brief current applied to an extracellular stimulation electrode placed in the molecular layer. With this stimulation paradigm, the increase in the evoked-EPSC amplitudes in the presence of 4-AP could be attributable to either augmented neurotransmitter release from the same number of PFs, an increase in the number of PFs activated by each stimulation, or both. The former can occur if 4-AP blocks a sufficient number of $\mathrm{K}^{+}$channels in PF terminals to broaden the presynaptic action potential. This will yield a larger $\mathrm{Ca}^{2+}$ influx, thus increasing the release probability at each synapse. Alternatively, if blockade of axonal $\mathrm{K}^{+}$channels with 4-AP were to increase their input resistance, 
A

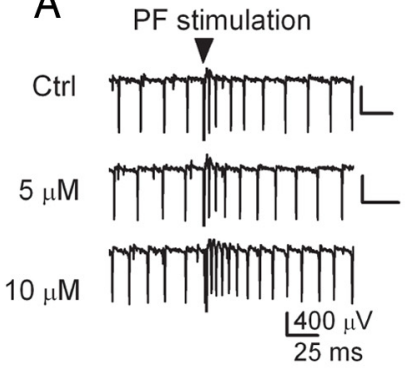

C

$\mathrm{E}$

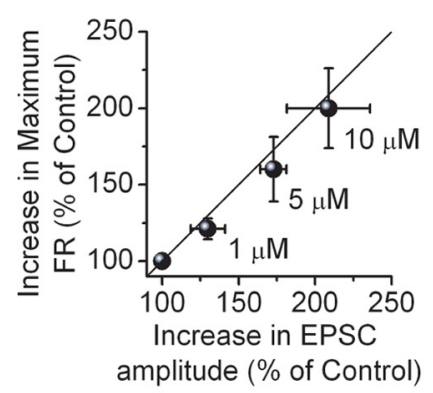

G

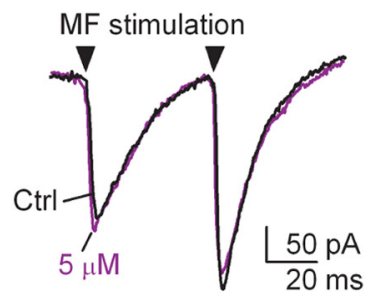

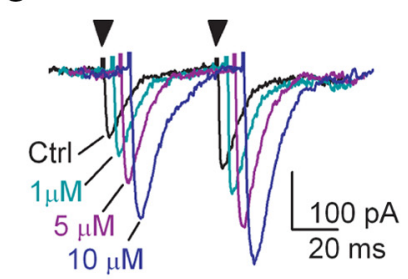

B

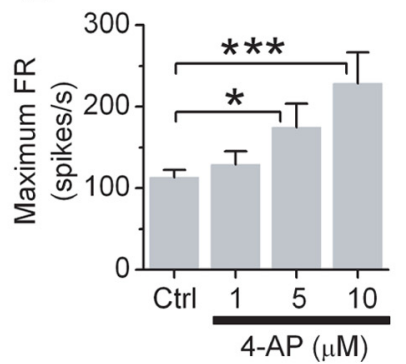

D

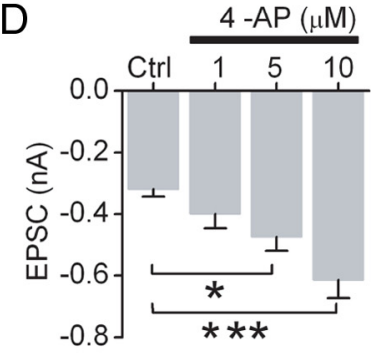

$\mathrm{F}$

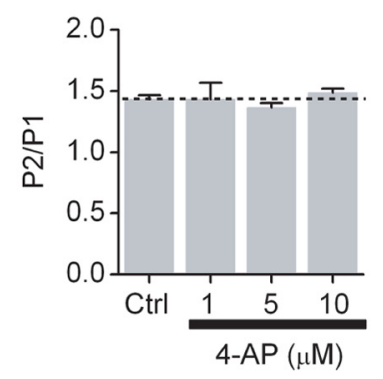

$\mathrm{H}$

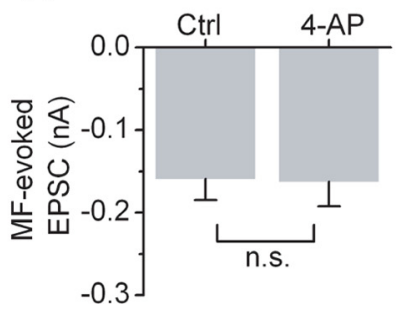

Figure 2. Therapeutic concentrations of 4-AP do not alter neurotransmitter release probability at parallel fiber synapses. $A$, Example traces of the response of an extracellularly recorded Purkinje cell to the electrical stimulation of PFs, in control conditions (Ctrl) and in increasing concentrations of 4-AP. $\boldsymbol{B}$, Average Purkinje cell maximum firing rate in response to PF stimulation under various conditions $\left(n=8\right.$ cells). ${ }^{*} p<0.05,{ }^{* * *} p<0.001$ (one-way ANOVA with Bonferroni's post test for multiple comparisons). C, Parallel fiber-evoked EPSCs recorded from a voltage-clamped Purkinje cell, under control conditions and sequential application of increasing concentrations of 4-AP. D, Average EPSC amplitudes in each condition reported above $(n=$ 12 cells). ${ }^{*} p<0.05,{ }^{* * *} p<0.001$. E, A comparison of the efficacy of 4-AP in increasing the amplitude of PF-evoked EPSCs versus PF-evoked increases in the firing rate of Purkinje cells. $\boldsymbol{F}$, Paired-pulse ratio of the amplitudes of the two EPSCs evoked by paired activation of PFs (50 ms apart) in voltage-clamped Purkinje cells. 4-AP did not alter this ratio at any of the concentrations examined. G, Examples of mossy fiber (MF)-evoked EPSCs in voltage-clamped Purkinje cells under control conditions and in the presence of $5 \mu \mathrm{M}$ 4-AP. $\boldsymbol{H}$, Average of the MF-evoked EPSCs before and after application of $5 \mu \mathrm{m}$ 4-AP. n.s., Not significant. $p>0.85$ (paired $t$ test).

more PFs might be brought to threshold with each stimulation. To delineate the potential contribution of each of these mechanisms to the increased EPSC amplitudes in the presence of 4-AP, we examined the paired-pulse ratio of two successive EPSCs before and after application of 4-AP. At the PF-to-Purkinje cell synapse changes in the paired-pulse ratio are faithfully correlated with changes in release probability (Foster et al., 2002). Under control conditions, when PFs were electrically activated with a pair of stimulation pulses $50 \mathrm{~ms}$ apart, the ratio of the peak amplitude of the second EPSC to the first was on average $1.43 \pm 0.03$ (Fig. $2 F$ ). This paired-pulse ratio was not significantly different in the presence of $1 \mu \mathrm{M} 4-\mathrm{AP}(1.43 \pm 0.14 ; p>0.3), 5 \mu \mathrm{M} 4-\mathrm{AP}(1.36 \pm 0.04$; $p>0.3)$, or even $10 \mu \mathrm{M} 4$-AP $(1.48 \pm 0.03 ; p>0.3)$. As a control we increased the concentration of 4-AP even further. As reported previously (Buckle and Haas, 1982), with $100 \mu \mathrm{M} 4$-AP the paired-pulse ratio reduced to $1.14 \pm 0.12$, and with $1 \mathrm{mM} 4-\mathrm{AP}$ the paired-pulse facilitation changed to significant paired-pulse depression (data not shown). These results indicate that at therapeutically relevant concentrations, 4-AP does not change the probability of neurotransmitter release at PF synapses. Instead, under our experimental conditions, 4-AP simply increased the number of PFs that are brought to threshold with each stimulation (although at the therapeutically relevant concentration of 1 $\mu \mathrm{M}$, the effects were small and not statistically significant). These effects of 4-AP are unlikely to be of physiological significance and possibly reflect the necessarily artifactual manner in which PFs were activated in these experiments. This is because in vivo granule cells, the neurons whose axons form PFs, are brought to threshold for firing of an action potential even by single quanta released from their mossy fiber synaptic inputs (Chadderton et al., 2004), and thus with therapeutic concentrations of 4-AP one would not anticipate a significant increase in the number of PFs activated under physiological conditions. In agreement with this supposition, as shown in Figure 2, $G$ and $H, 5 \mu \mathrm{M}$ 4-AP failed to potentiate PF-evoked EPSCs in voltage-clamped Purkinje cells when the stimulation electrode was positioned in the white matter to activate the mossy fiber inputs to the granule cells (control EPSC amplitude, $159 \pm 26 \mathrm{pA}$ vs $5 \mu \mathrm{M} 4$-AP, $162 \pm 30 \mathrm{pA} ; p>$ 0.85 , paired $t$ test; $n=3$ cells). Similarly, the paired-pulse ratios of EPSCs evoked by mossy fiber stimulation were not affected after addition of $5 \mu \mathrm{M} 4$-AP (control, $1.18 \pm 0.05$ vs 4 -AP, $1.21 \pm 0.4$; $p>0.1)$.

Comparable experiments demonstrated that therapeutic concentrations of 4-AP do not alter release probability at the Purkinje cell to DCN synapses (see supplemental material 1, available at www.jneurosci.org).

\section{Therapeutic concentrations of 4-AP increase the precision of Purkinje cell pacemaking in tottering mice}

The experiments described above show that therapeutic concentrations of 4-AP do not increase the excitability or rate of activity of Purkinje cells. Moreover, 4-AP does not increase the release probability at the PF-to-Purkinje cell or the Purkinje cell-toDCN synapses. Combined, in contrast with what is widely believed (Strupp and Brandt, 2006; Jen et al., 2007; Strupp et al., 2007,2008 ), our data suggest that it is unlikely that the therapeutic mode of action of 4-AP in EA2 is by increasing the inhibitory drive of Purkinje cells onto DCN neurons. An alternative hypothesis regarding the therapeutic mode of action of 4-AP proposed by Otis and Jen (2006) is that 4-AP restores the precision of Purkinje cell pacemaking by broadening the duration of action potentials. This mode of action is based on the findings that loss in the precision of Purkinje cell pacemaking has been suggested to contribute to the motor symptoms of EA2 (Walter et al., 2006). Indeed, in vivo cerebellar perfusion of the $\mathrm{K}_{\mathrm{Ca}}$ channel activator 1-ethyl-2-benzimidazolinone (EBIO) restores the precision of Purkinje cell pacemaking and significantly improves motor function in mouse models of EA2 (Walter et al., 2006). This potential 
therapeutic mode of action of 4-AP, although not experimentally examined, has been dismissed.

To test this hypothesis, we examined the activity of Purkinje cells in acutely prepared cerebellar slices from the $\mathrm{tg} / \mathrm{tg}$ mice. These mice suffer from a spontaneous mutation in the pore-forming subunit of the P/Q-type $\mathrm{Ca}^{2+}$ channel, which reduces their current density (Fletcher et al., 1996), and are one of the most studied and best established models of EA2 (Jinnah et al., 2005; Pietrobon, 2005). Similar to EA2 patients, the $\operatorname{tg} / \mathrm{tg}$ mice show baseline ataxia and episodes of severe dyskinesia, which are triggered by stress, caffeine, and ethanol (Fureman et al., 2002; Shirley et al., 2008). Although the mutation in $t g / t g$ mice results in a very large decrease in the $\mathrm{P} / \mathrm{QCa}^{2+}$ current density and more severe episodes of dyskinesia than typically seen in EA2 patients, these mice have served as a very useful and reliable model of EA2 both for examining the etiology of the disorder and also for surveying therapeutic options. In fact, acute administration of 4-AP is as effective in alleviating the motor symptoms of the $\mathrm{tg} / \mathrm{tg}$ mice as it is in humans (Weisz et al., 2005).

Consistent with observations in other mutant animal models of EA2 such as the ducky and leaner mice (Walter et al., 2006; Ovsepian and Friel, 2008), we found that the intrinsic pacemaking of $t g / t g$ Purkinje cells was also highly erratic (Fig. $3 A-C$ ). Thus, the coefficient of variation (CV) of the interspike intervals in $t g / t g$ Purkinje cells was $0.18 \pm 0.03$ (Fig. $3 C)(n=15$ cells), a value significantly higher than $0.07 \pm 0.01$ seen in age-matched wt Purkinje cells $(p<0.001 ; n=22$ cells $)$. Application of 4-AP, in a concentrationdependent manner, made the firing of tg/tg Purkinje cells more regular (Fig. $3 B, C)$. Even at a concentration of $1 \mu \mathrm{M}$, 4-AP reduced the coefficient of variation of the interspike intervals to $0.10 \pm 0.01(p<0.001 ; n=15$ cells $) .4-\mathrm{AP}$ at $5 \mu \mathrm{M}$ reduced the coefficient of variation of the interspike intervals to $0.07 \pm 0.01(p<0.001 ; n=20$ cells $)$, and at $10 \mu \mathrm{M}$ to $0.05 \pm 0.01$ ( $p<0.001 ; n=12$ cells). The latter values were not statistically different from that seen in age-matched wt Purkinje cells $(p>$ 0.1 ). Whereas $10 \mu \mathrm{M} 4$-AP reduced the firing rate of $\operatorname{tg} / \mathrm{tg}$ Purkinje cells from an average of $69.2 \pm 4.5$ spikes per second to $46.1 \pm 2.7$ spikes per second $(p<0.01)$, the effects of 1 and $5 \mu \mathrm{M} 4$-AP on the firing rate were minor and not statistically significant $(1 \mu \mathrm{M}$ 4-AP, $64.6 \pm 5.1$ spikes per second; $5 \mu \mathrm{M}$ 4-AP, $62.4 \pm 4.8$ spikes per second; $p>0.1$ ) (Fig. $3 D$ ). Thus, $4-\mathrm{AP}$ at the therapeutically relevant concentration of $1 \mu \mathrm{M}$ significantly improves the precision of pacemaking of $\mathrm{tg} / \mathrm{tg}$ Purkinje cells. In a separate set of studies, we used low concentrations of cadmium to block $\mathrm{Ca}^{2+}$ channels to decrease the precision of pacemaking in rat Purkinje cells (Walter et al., 2006). We found that the precision of pacemaking in these cells was restored with the same concen- trations of 4-AP that were effective in $t g / t g$ mice (see supplemental material 2, available at www.jneurosci.org).

\section{Therapeutic concentrations of 4-AP broaden the} action potential and increase the amplitude of afterhyperpolarization

Activators of $\mathrm{Ca}^{2+}$-dependent $\mathrm{K}^{+}$channels restore the precision of Purkinje cell pacemaking in EA2 animal models by increasing the amplitude of action potential AHP (Walter et al., 2006). We tested the possibility that by blocking a subset of $\mathrm{K}^{+}$channels 4-AP restores the precision of Purkinje cell pacemaking by broadening their action potentials, thus increasing the amplitude of their AHPs.

We first examined the extracellularly recorded spikes. These voltage deflections correspond to the derivative of the actual membrane potential of the target Purkinje cell. Thus, the start of the negative voltage deflection corresponds to the start of the rising phase of the action potential, and the positive peak of the signal relates to the time at which the rate of membrane potential 
A
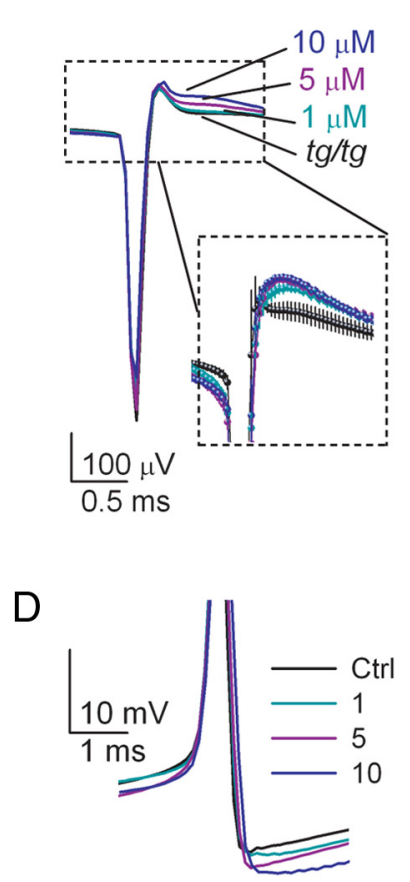

F

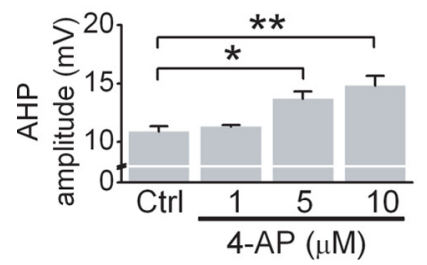

B
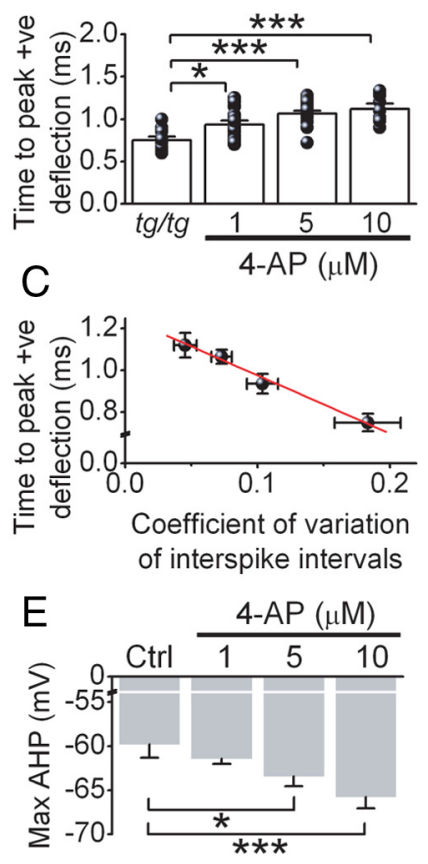

G

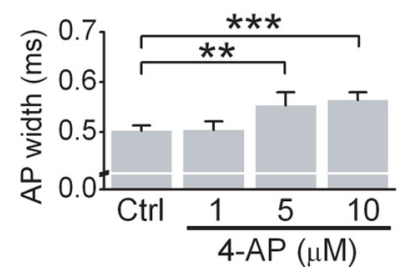

Figure 4. 4-AP broadens action potentials in Purkinje cells. $\boldsymbol{A}$, Averaged extracellularly recorded action potentials in a $\mathrm{tg} / \mathrm{tg}$ Purkinje cell under control conditions and in the presence of different concentrations of 4-AP. Inset, The average of the normalized waveforms in each condition. $\boldsymbol{B}$, Average and individual values of time to peak positive deflection, measured as indicated at the top of the inset in $A$. C, Comparison of the efficacy of 4-AP in improving the precision of Purkinje cell pacemaking (represented by the coefficient of variation of interspike intervals) and its efficacy in prolonging the duration of the spike. Red trace represents the linear fit $(r=$ $-0.99 ; p=0.007)$. $\boldsymbol{D}$, Averaged action potentials recorded in whole-cell configuration in a wt juvenile rat Purkinje cell, in control conditions, and after the application of therapeutic concentrations of 4-AP. $\boldsymbol{E}$, Average and individual values of maximum AHP potentials in six Purkinje cells. $\boldsymbol{F}$, Average and individual values of the AHP amplitudes of the same cells in $\boldsymbol{E}$. $\boldsymbol{G}$, Average and individual values of the action potential width of the same cells in $E$. ${ }^{*} p<0.05$; ${ }^{* *} p<0.01$; ${ }^{* * *} p<0.001$ (one-way ANOVA with Bonferroni's post test for multiple comparisons).

repolarization is the greatest, that is, the time at which the net outward ionic current is at its maximum. The positive voltage thereafter corresponds with the continuation of the down stroke of the action potential and its AHP. Compared with the direct examination of the action potential width with whole-cell recordings, using the extracellular signals has the advantage that it avoids dialysis of the cell and the associated changes in $\mathrm{Ca}^{2+}$ buffering and homeostasis. Quantification of the data demonstrated that 4 -AP broadens the action potential in a concentration-dependent manner (Fig. $4 A, B$ ). The time to the peak positive voltage deflection (measured as the time taken from the beginning of the negative deflection to the peak of the positive deflection) increased from an average of $0.75 \pm 0.04 \mathrm{~ms}$ under control conditions to $0.94 \pm 0.05 \mathrm{~ms}$ in $1 \mu \mathrm{M} 4$-AP $(p<0.05)$, and to $1.06 \pm 0.03 \mathrm{~ms}$ and $1.12 \pm 0.06 \mathrm{~ms}$ with 5 and $10 \mu \mathrm{M} 4-\mathrm{AP}$, respectively ( $p<0.001$ for both cases). Consistent with the hy-

pothesis that broadening of the action potential was the cause of improved pacemaking, there was a clear linear relationship between the average duration and the coefficient of variation (Fig. $4 C)$. In agreement with the notion that 4-AP prolongs the AHP, in the presence of $4-\mathrm{AP}$, the positive deflections of the extracellular signals were longer (Fig. $4 A$, inset).

As a complementary approach, we also examined the effect of 4-AP on the action potential waveform using whole-cell currentclamp recordings, taking into consideration the caveat that whole-cell recordings do dialyze the cells and affect $\mathrm{Ca}^{2+}$ buffering (and may also alter other intracellular biochemical signaling pathways). As can be noted in the sample traces shown, 4-AP dose-dependently increased the width of the action potential and also the absolute AHP potential (Fig. $4 D$ ). The average maximum AHP potential in control conditions was $-59.8 \pm 1.6 \mathrm{mV}(n=6$ cells), which, after application of $1 \mu \mathrm{M} 4$-AP, increased to $-61.4 \pm 0.6 \mathrm{mV}$ (Fig. $4 E$ ). 4 -AP at 5 and $10 \mu \mathrm{M}$ increased the maximum AHP potential further to $-63.4 \pm 1.1 \mathrm{mV}(p<0.05)$ and $-65.8 \pm 1.3 \mathrm{mV}(p<0.001)$, respectively. In addition to the absolute AHP potential, the AHP amplitude (measured from threshold) increased significantly with 4-AP (Fig. 4F) (control, $10.9 \pm 0.5 \mathrm{mV} ; 1 \mu \mathrm{M} 4-\mathrm{AP}, 11.3 \pm 0.2 \mathrm{mV} ; 5 \mu \mathrm{M} 4-\mathrm{AP}, 13.7 \pm 0.6$ $\mathrm{mV}, p<0.05 ; 10 \mu \mathrm{M} 4-\mathrm{AP}, 14.8 \pm 0.9 \mathrm{mV}, p<0.01)$. Finally, the width of the action potential (measured as the time taken from threshold to $10 \%$ peak action potential amplitude during the down stroke of action potential) also increased when 4-AP was added (Fig. 4G) (control, $0.50 \pm 0.01 \mathrm{~ms} ; 1 \mu \mathrm{M} \mathrm{4-AP,} 0.51 \pm$ $0.017 \mathrm{~ms} ; 5 \mu \mathrm{M} 4-\mathrm{AP}, 0.55 \pm 0.03 \mathrm{~ms}, p<0.01 ; 10 \mu \mathrm{M} 4-\mathrm{AP}$, $0.56 \pm 0.015 \mathrm{~ms}, p<0.001)$.

Collectively the data presented demonstrate that at concentrations effective in the treatment of cerebellar-related motor disorders, 4-AP increases the regularity of a Purkinje cell's pacemaking by prolonging the duration of its action potentials. The broader action potentials are accompanied with larger AHPs, presumably because of the greater $\mathrm{Ca}^{2+}$ influx associated with the broader action potentials and the additional activation of $\mathrm{Ca}^{2+}$ dependent $\mathrm{K}^{+}$conductances. This larger $\mathrm{Ca}^{2+}$ influx is likely to compensate, in part, for the reduced P/Q-type $\mathrm{Ca}^{2+}$ current density associated with EA2 mutations (Fletcher et al., 1996; Dove et al., 1998; Barclay et al., 2001).

\section{Therapeutic concentrations of 4-AP most likely block $\mathrm{K}_{\mathrm{v}} 1.5$ potassium channels}

Based on the affinity of 4-AP for block of various $\mathrm{K}^{+}$channel subtypes (Coetzee et al., 1999) and the expression pattern of channels in the cerebellum, and specifically in Purkinje cells (Madeja et al., 1997; Chung et al., 2001, 2005; Martina et al., 2003; Hurlock et al., 2008), the most likely target of therapeutic concentrations of 4-AP are the $\mathrm{K}_{\mathrm{v}} 1$ family of $\mathrm{K}^{+}$channels, specifically the $\mathrm{K}_{\mathrm{v}} 1.5$ channels that have the highest affinity for 4-AP. To a much lesser extent, $\mathrm{K}_{\mathrm{v}} 3.1$ or $\mathrm{K}_{\mathrm{v}} 3.3$ channels could also be the targets of 4-AP. Therefore, we tested whether the $\mathrm{K}_{\mathrm{v}} 1.5$ channel blocker 2-isopropyl-5-methylcyclohexyl (DPO) (Lagrutta et al., 2006) could substitute for 4-AP in restoring the precision of pacemaking. We monitored the activity of normal Purkinje cells in slices by extracellular recordings, and as before applied cadmium to partially block $\mathrm{Ca}^{2+}$ channels and make the firing of Purkinje cells irregular. This was reflected as an increase the coefficient of variation of the interspike intervals (Fig. 5A).

Bath application of $5 \mu \mathrm{M}$ DPO decreased the coefficient of variation Purkinje cell firing to levels comparable to control conditions (Fig. $5 A, B$ ) without altering the firing rate (Fig. $5 C$ ). The coefficient of variation of interspike intervals in control condi- 
tions was $0.052 \pm 0.005$, which, after application of cadmium, increased to $0.114 \pm 0.007$ (Fig. $5 B)(n=6-12$ cells; $p<0.001)$. Application of DPO reduced it to $0.071 \pm 0.003$ ( $p<0.001$ vs cadmium $)$. Furthermore, application of $10 \mu \mathrm{M} 4$-AP after DPO did not change further reduce the coefficient of variation of interspike intervals $(\mathrm{CV}, 0.07 \pm 0.003$ after application of 4 -AP, $p<0.001$ vs cadmium, $p>$ 0.1 vs DPO). This occlusion of effects suggests (but of course does not prove) that the effects of 4-AP were likely mediated by the blockade of $\mathrm{K}_{\mathrm{v}} 1$ channels.

\section{The therapeutic actions of 4-AP in vivo are consistent with improving the precision of pacemaking}

The data presented above suggest that by restoring the precision of Purkinje cell pacemaking, the therapeutic mode of action of 4-AP in EA2 may be the same as that of EBIO, an activator of $\mathrm{Ca}^{2+}$ dependent $\mathrm{K}^{+}\left(\mathrm{K}_{\mathrm{Ca}}\right)$ channels. EBIO improved the precision of Purkinje cell pacemaking in slices of EA2 mutant mice and lessened their ataxia when chronically perfused into their cerebellum in vivo (Walter et al., 2006). Although in vivo perfusion of EBIO could, in principle, affect other cerebellar neurons such as DCN cells, at the concentrations used, their most likely target were cerebellar Purkinje cells (Alvina and Khodakhah, 2008). If the primary mode of action of 4-AP is indeed restoring the precision of Purkinje cell pacemaking, then one would anticipate that the beneficial effects of 4-AP in reducing motor symptoms should not be additive to those of $\mathrm{K}_{\mathrm{Ca}}$ channel activators; i.e., coadministration of 4-AP with a $\mathrm{K}_{\mathrm{Ca}}$ channel activator should only be as effective as the sole administration of either drug with the highest efficacy. We tested this hypothesis by examining whether treatment of $\mathrm{tg} / \mathrm{tg}$ mice concurrently with both a $\mathrm{K}_{\mathrm{Ca}}$ channel activator and 4-AP was more effective in reducing their motor symptoms than with either one alone.

We first calculated the concentration of 4-AP that needed to be added to the drinking water of $t g / t g$ mice to achieve the therapeutic concentration of 4 -AP found in the plasma of patients $(\sim 50 \mathrm{ng} / \mathrm{ml})$. Given that in rodents the half-life of 4 -AP is $\sim 2 \mathrm{~h}$ (Capacio et al., 1996), and considering that the $t g / t g$ mice weigh an average of $20 \mathrm{~g}$, we estimated that a daily 4 -AP consumption of $\approx 0.1 \mathrm{mg}$ will result in an equivalent, but temporally uniform, 4-AP plasma concentration in mice. Since, on average, the $\mathrm{tg} / \mathrm{tg}$ mice consume $\sim 2.5 \mathrm{ml}$ of water daily, we supplied them with a $425 \mu \mathrm{M}$ solution of 4-AP, which they readily drank.

Patients affected by EA2 not only have episodic attacks of dyskinesia, but also show mild baseline ataxia that progress in severity with time (Jen et al., 2004). Thus, we examined the efficacy of oral administration of 4-AP in alleviating baseline ataxia in the $\mathrm{tg} / \mathrm{tg}$ mice using an accelerating rotarod paradigm (Walter et al., 2006; Crawley, 2008). The performance of $\operatorname{tg} / \operatorname{tg}(n=13)$ but not the wt mice $(n=14)$ increased on the rotarod when 4 -AP was added to their drinking water (Fig. 6A). During the pretreatment period, the performance of the $\mathrm{tg} / \mathrm{tg}$ on the rotarod reached on average $10.9 \pm 0.8 \mathrm{rpm}$ (Fig. $6 \mathrm{~B}$ ), whereas during treatment with
4-AP it increased to $13.8 \pm 0.9 \mathrm{rpm}(p<0.05)$. 4-AP had no effect on the performance of the wt mice (pretreatment, $34.5 \pm 0.9$ rpm; 4 -AP, $34.9 \pm 1.4 \mathrm{rpm} ; p>0.1$ )

We then set out to examine whether the beneficial effects of 4-AP were additive to those of the $\mathrm{K}_{\mathrm{Ca}}$ channel activator $\mathrm{CHZ}$ (Syme et al., 2000). CHZ is an analog of EBIO (Cao et al., 2001) and crosses the blood-brain barrier (Chou et al., 2004), thus allowing it to be supplied to mice by adding it to their drinking water. In experiments performed in acutely prepared cerebellar slices, we recently determined the concentrations of $\mathrm{CHZ}$ that restores the precision of pacemaking in $t g / t g$ Purkinje cells (Alviña and Khodakhah, 2010). Moreover, using this information, and taking into account the pharmacokinetics of $\mathrm{CHZ}$ (Wan et al., 2006), we have found that supplementing the drinking water of the $\mathrm{tg} / \mathrm{tg}$ mice with $15 \mathrm{~mm} \mathrm{CHZ} \mathrm{markedly} \mathrm{improves}$ their performance on the rotarod (Alviña and Khodakhah, unpublished observation). We thus examined whether in the same group of mice treated with 4-AP the beneficial effects of $\mathrm{CHZ}$ were additive. Although the performance of the $\mathrm{tg} / \mathrm{tg}$ mice on the rotarod improved further when, in addition to $4-\mathrm{AP}, \mathrm{CHZ}$ was also added to their drinking water, this increase was small and just shy of being statistically different (from $13.8 \pm 0.9 \mathrm{rpm}$ in 4 -AP alone to $16.2 \pm 0.9 \mathrm{rpm}$ with the addition of $\mathrm{CHZ} ; p=0.06)$. The performance of $\mathrm{tg} / \mathrm{tg}$ mice continued at its high level when 4-AP was removed and the mice received only $\mathrm{CHZ}(16.2 \pm 0.8 \mathrm{rpm}$; $p>0.1$ vs $4 \mathrm{AP}$ and $\mathrm{CHZ}$ combined), suggesting that there was little benefit in combining the two drugs. Throughout the various treatments, the performance of wt mice did not change (pretreatment, $34.5 \pm 0.9 \mathrm{rpm}$; 4 -AP alone, $34.9 \pm 1.4 \mathrm{rpm}$; 4 -AP and $\mathrm{CHZ}, 34.9 \pm 1.1 \mathrm{rpm}$; CHZ alone $35.0 \pm 1.1 \mathrm{rpm}$; posttreatment, 
A

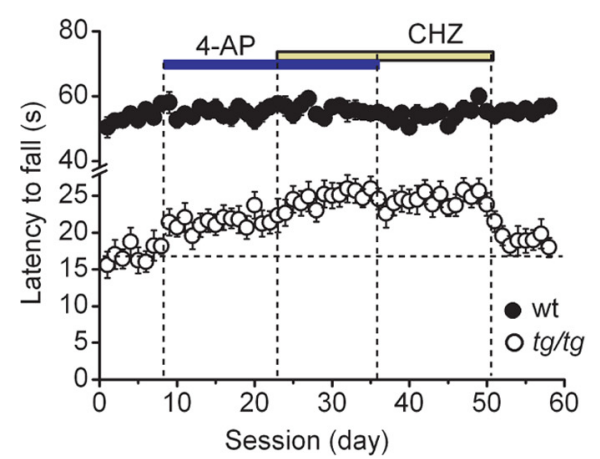

B

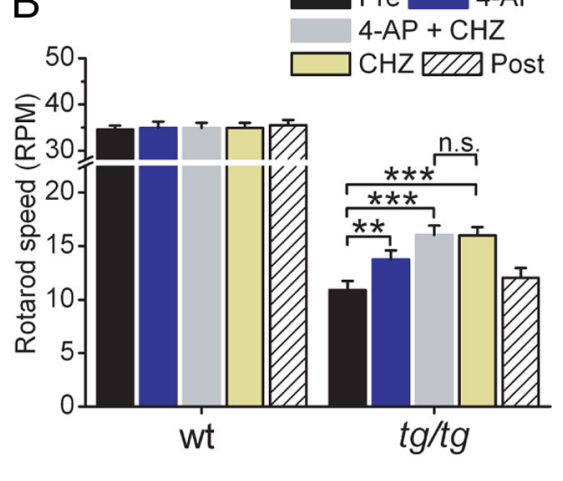

Figure 6. The therapeutic efficacy of orally administered 4-AP in improving basal motor performance in $\mathrm{tg} / \mathrm{tg}$ mice is not additive to that of $\mathrm{CHZ}$. $A$, The performance of $\operatorname{tg} / \mathrm{tg}(n=13)$ and wt mice $(n=14)$ was measured using the accelerating rotarod paradigm. After $8 \mathrm{~d}$ of receiving normal drinking water, the drinking water was supplemented with 4-AP, 4-AP and CHZ combined, and $\mathrm{CHZ}$ alone as denoted with colored vertical bars. Each treatment lasted for 2 weeks. B, Maximum speed achieved on the rotarod during each treatment. The average value was obtained by averaging the second week of each treatment period. ${ }^{* *} p<0.01$; ${ }^{* * *} p<0.001$ (one-way ANOVA with Bonferroni's correction). n.s., Not significant.

$35.5 \pm 1.1 \mathrm{rpm} ; p>0.5$ for all treatments vs pretreatment). Thus, at least with respect to improving baseline motor function, the data are consistent with the hypothesis that both 4-AP and $\mathrm{CHZ}$ may have a common mode of action.

It is plausible that although the mode of action of 4-AP in alleviating baseline ataxia may be the same as that of $\mathrm{K}_{\mathrm{Ca}}$ activators, 4-AP may have a different mechanism of action in preventing the episodes of dyskinesia associated with EA2. We thus similarly compared the efficacy of 4-AP alone with that of its coadministration with $\mathrm{CHZ}$ in reducing the frequency, severity, and duration of stress-induced episodes of dyskinesia triggered by the rotarod session in $\mathrm{tg} / \mathrm{tg}$ mice (Fig. $7 \mathrm{~A}$ ). Both 4-AP and $\mathrm{CHZ}$ significantly reduced the average overall severity of symptoms after stress (Fig. $7 B$ ), although $\mathrm{CHZ}$ produced a slightly larger reduction, and there was little benefit in the coadministration of the two drugs.

To scrutinize the impact of these treatments on frequency, duration, and severity of episodes, we first analyzed all attacks of dyskinesia regardless of their individual severity. 4-AP treatment reduced the frequency of attacks to $81.7 \pm 5.2 \%$ of the baseline pretreatment values (Fig. $7 C)(p<0.01)$. Addition of $\mathrm{CHZ}$ to 4 -AP further reduced the frequency of attacks to $59.6 \pm 7.8 \%$ ( $p<0.001$ vs pretreatment). When $\mathrm{CHZ}$ was administered without 4 -AP, the frequency of all attacks were $50.0 \pm 5.4 \%$ of baseline ( $p<0.001$ vs pretreatment), a value statistically different when compared with the 4-AP treatment alone $(p<0.05)$, but not statistically different from $\mathrm{CHZ}$ and 4 -AP combined $(p>$ 0.1 ). After returning mice to normal drinking water, the frequency of attacks in the $\mathrm{tg} / \mathrm{tg}$ mice increased to its pretreatment values (98.5 $\pm 1.5 \% ; p>0.1$ vs pretreatment). In addition, treatment with both 4-AP and CHZ comparably reduced the severity (Fig. 7D) and the duration of all attacks of dyskinesia (Fig. 7E).

The occurrence of the most severe attacks (those with a maximum score of $\geq 3.5$ ) was also reduced by all three treatments (Fig. $7 F$ ). Even though both $4-\mathrm{AP}$ and $\mathrm{CHZ}$ were effective in reducing the frequency of these severe attacks, we found that $\mathrm{CHZ}$ was slightly more effective than 4 -AP alone $(22.1 \pm 3.1 \%$ of baseline vs $33.7 \pm 3.2 \%$; $p<0.05$ ), and there was no advantage in coapplication of 4 -AP with $\mathrm{CHZ}$. In all cases, when severe attacks occurred they were as severe as those before treatment (Fig. 7G), although their duration was significantly and comparably briefer with all three treatments (Fig. $7 H$ ).

The pie charts in Figure $7 I$ directly compare the efficacy of 4-AP, CHZ, and 4-AP with $\mathrm{CHZ}$ in reducing the frequency of stress-evoked attacks of dyskinesia in $\mathrm{tg} / \mathrm{tg}$ mice. Although both 4-AP and CHZ potently reduce the frequency of attacks, $\mathrm{CHZ}$ is much more effective in increasing the percentage of attack-free sessions in which stress did not cause any motor impairment whatsoever (50\% in $\mathrm{CHZ}$ alone vs $18.3 \%$ during 4 -AP). Moreover, there was no benefit in coapplication of the two compounds.

In summary, our findings are consistent with the hypothesis that both $\mathrm{CHZ}$ and 4-AP have a common mode of action. Moreover, it is plausible and perhaps quite likely that their therapeutic efficacies are the consequence of their ability to improve the precision of pacemaking in Purkinje cells.

\section{Discussion \\ Etiology of EA2}

EA2 is the most prevalent form of episodic ataxia (Jen et al., 2007). The symptoms of EA2 patients are mostly cerebellar in origin, and in animal models of EA2 removal of the cerebellum, or genetic elimination of Purkinje cells eliminates the episodes of dyskinesia (Campbell et al., 1999; Grusser-Cornehls and Baurle, 2001). The $\mathrm{Ca}^{2+}$ channels that are affected in EA2 are highly expressed throughout the CNS (Evans and Zamponi, 2006) and are particularly enriched in axon terminals and in cerebellar Purkinje cells (Mori et al., 1991; Usowicz et al., 1992; Stea et al., 1994). $\mathrm{Ca}^{2+}$ influx primarily through these channels mediates synaptic transmission at CNS nerve endings (Evans and Zamponi, 2006) and initial hypotheses regarding the etiology of EA2 focused on the dysfunction of cerebellar synapses. However, although alterations in synaptic transmission at the parallel and climbing fiber synapses are notable in some animal models of EA2, they are relatively minor and not as profound as that anticipated, mainly as a consequence of functional compensation by other voltage-gated $\mathrm{Ca}^{2+}$ channels (Matsushita et al., 2002; Ovsepian and Friel, 2008).

Within the cerebellum P/Q-type $\mathrm{Ca}^{2+}$ channels are particularly enriched in Purkinje cells, where the dendritic ones generate $\mathrm{Ca}^{2+}$ action potentials (Llinas and Sugimori, 1980), and the somatic ones provide the sole source of $\mathrm{Ca}^{2+}$ for activation of $\mathrm{K}_{\mathrm{Ca}}$ channels (Womack et al., 2004). Indeed, in Purkinje cells the net $\mathrm{Ca}^{2+}$-dependent current associated with each action potential is outward (Raman and Bean, 1999), and the P/Q-channelmediated activation of $\mathrm{K}_{\mathrm{Ca}}$ channels is required to maintain the precision of their pacemaking (Womack and Khodakhah, 2004; Walter et al., 2006). In animal models of EA2, the precision of Purkinje pacemaking is significantly deteriorated, and there is little evidence for the presence of compensatory mechanisms (Hoebeek et al., 2005; Walter et al., 2006). It has therefore been suggested that irregular firing of cerebellar Purkinje cells contributes to motor symptoms associated with EA2 (Walter et al., 2006). 
Therapeutic approaches to EA2

There are presently few therapeutic options available for EA2 patients, with acetazolamide (ACTZ) and 4-AP constituting the most commonly used drugs (Jen et al., 2007; Strupp et al., 2007). Many patients respond well to ACTZ, which both improves some of the baseline symptoms and reduces the frequency of episodes of dyskinesia (Zasorin et al., 1983; Friedman and Hollmann, 1987; Harno et al., 2004). However, with time, many patients become nonresponsive to ACTZ treatment (Jen et al., 2007; Strupp et al., 2007). The mechanism of action of ACTZ in the treatment of EA2 is not understood. Because ACTZ is a carbonic anhydrase inhibitor (Maren, 1967), it is suggested that ACTZ prevents elevations in the intracellular pH (Strupp et al., 2007), although it is not clear why this should be helpful.

More recently 4-AP has been used to reduce the symptoms of EA2 (Strupp et al., 2004; Lohle et al., 2008), and it is found to be effective in both improving baseline motor coordination and in reducing the frequency and severity of the episodic attacks (Glasauer et al., 2005; Strupp et al., 2007; Lohle et al., 2008). However, 4-AP has to be used with caution since as a $\mathrm{K}^{+}$channel blocker it can be epileptogenic (Bever et al., 1994; Judge and Bever, 2006).

The therapeutic mode of action of 4-AP 4-AP was first prescribed based on the notion that, because of the reduced $\mathrm{Ca}^{2+}$ current density associated with EA2 mutations, Purkinje cells must be less active (Strupp et al., 2004, 2005; Glasauer et al., 2005). The remarkable efficacy of 4-AP in alleviating cerebellar motor symptoms in several patients has indirectly substantiated this presumed mode of action (Strupp et al., 2004; Glasauer et al., 2005; Kalla et al., 2007; Lohle et al., 2008). The data presented here demonstrate that therapeutic concentrations of 4-AP do not alter the rate of activity of Purkinje cells. Nor does 4-AP, at the relevant concentrations, alter synaptic transmission at the parallel fiber-to-Purkinje cell or the Purkinje cell-to-DCN synapses. The only functional consequence of application of 4-AP that we could discern was that of restoring the precision of pacemaking in the EA2 mutant Purkinje cells by blocking $\mathrm{K}^{+}$channels and prolonging the AP and increasing its AHP.

The therapeutic mode of action of 4-AP described here is consistent with the finding that in mouse models of EA2, direct perfusion of the $\mathrm{K}_{\mathrm{Ca}}$ channel activator EBIO into the cerebellum to improve the precision of Purkinje cell pacemaking lessens their
A

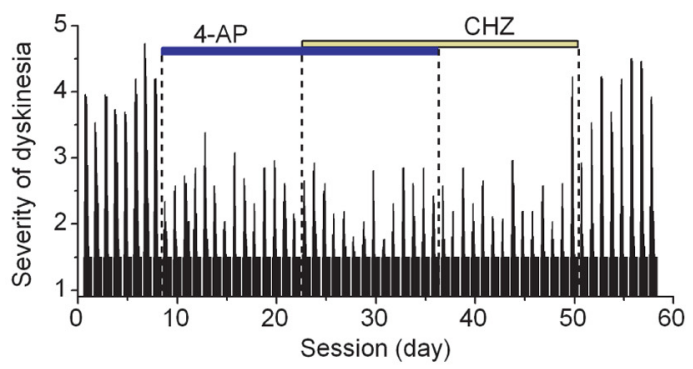

B

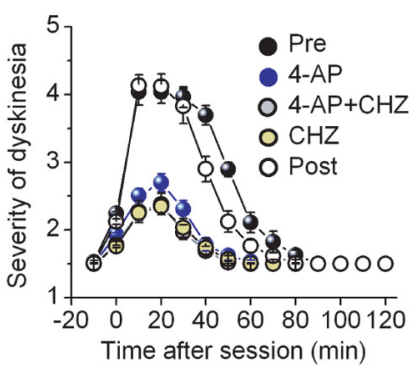

All episodes of dyskinesia

C
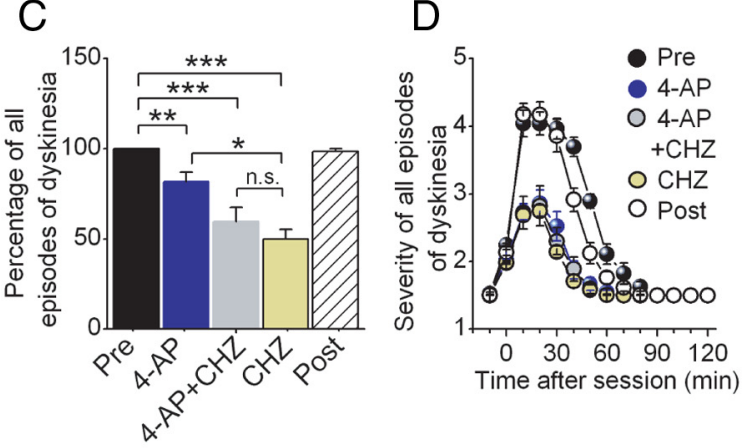

E

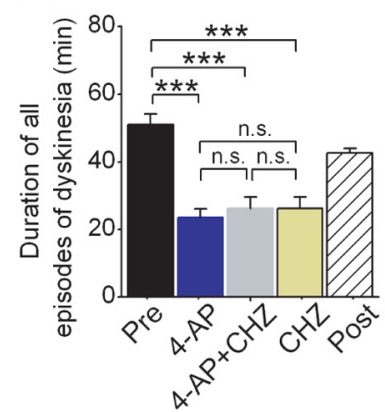

\section{Episodes of dyskinesia $\geq 3.5$}

$\mathrm{F}$
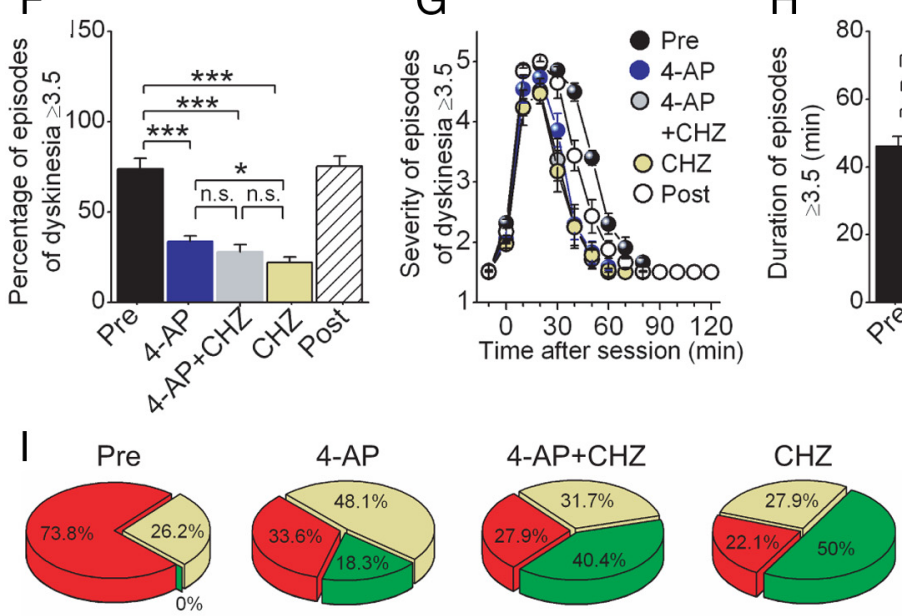

No attack
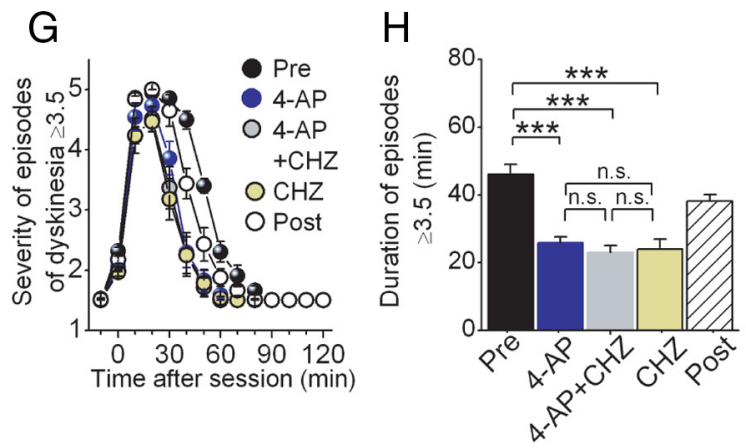

Figure 7. The therapeutic efficacy of orally administered 4-AP in reducing the frequency and severity of stress-induced episodes of dyskinesia in $\mathrm{tg} / \mathrm{tg}$ mice is not additive to that of $\mathrm{CHZ}$. $\boldsymbol{A}$, The stress-triggered attacks of dyskinesia were quantified at $10 \mathrm{~min}$ intervals for the same mice examined using the accelerating rotarod paradigm reported in Figure 4 . The beginning and end of each treatment is indicated with colored bars on top. $B$, The average severity of dyskinesia during each period for the same $\mathrm{tg} / \mathrm{tg}$ mice shown in $\boldsymbol{A}$. $\boldsymbol{C}$, The average frequency of occurrence of an episode of dyskinesia after the rotarod session, regardless of the severity of the attack. $\boldsymbol{D}$, The average severity of all attacks of dyskinesia before, during, and after the three different treatments. $\boldsymbol{E}$, The duration of all attacks of dyskinesia shown in $\boldsymbol{D}$. $\boldsymbol{F}$, The average frequency of occurrence of a severe episode of dyskinesia (dyskinesia score $\geq 3.5$ ) triggered by the rotarod session. $\boldsymbol{G}$, The average severity of the attacks shown in $\boldsymbol{F}$. $\boldsymbol{H}$, Average duration of severe episodes of dyskinesia. ${ }^{*} p<0.05 ;{ }^{* *} p<0.01 ;{ }^{* * *} p<0.001$ (one-way ANOVA followed by Bonferroni's post test). ns, Not significant. I, Summary comparison of the relative efficacies of 4-AP and CHZ in reducing stress-evoked attacks of dyskinesia in $\mathrm{tg} / \mathrm{tg}$ mice. Frequency of sessions in which $\mathrm{tg} / \mathrm{tg}$ mice were free of symptoms (no attack) or had an episode of dyskinesia with a score $<3.5$ (mild) or one with a score $\geq 3.5$ (severe) with various treatments. motor symptoms (Walter et al., 2006). The fact that the beneficial effects of $\mathrm{CHZ}$ and 4-AP were not additive also corroborates the hypothesis that the mode of action of 4-AP might be the same as EBIO (although this does not by any means constitute proof). The greater efficacy of $\mathrm{CHZ}$ compared with 4-AP in alleviating 
motor symptoms of the $\mathrm{tg} / \mathrm{tg}$ mice (even though in slices their efficacies in restoring the precision of Purkinje cell pacemaking is comparable) may be attributable to differences in their pharmacokinetics, in their ability to cross the blood-brain barrier, or differences in their potential side effects in vivo.

\section{$\mathrm{K}_{\mathrm{v}} 1$ channel blockers as $\mathrm{K}^{+}$therapeutic agents in EA2}

Based on its affinity for $\mathrm{K}^{+}$channels, the most likely target of therapeutic concentrations of $4-\mathrm{AP}$ is the $\mathrm{K}_{\mathrm{v}} 1$ family of $\mathrm{K}^{+}$channels (Coetzee et al., 1999), and possibly the $\mathrm{K}_{\mathrm{v}} 1.5 \mathrm{~K}^{+}$channels that are thought to be expressed in Purkinje cells (Madeja et al., 1997; Chung et al., 2001, 2005). The efficacy of the $\mathrm{K}_{\mathrm{v}} 1.5$ channel blocker DPO (Lagrutta et al., 2006) in restoring the precision of pacemaking in Purkinje cells substantiates the hypothesis that therapeutic concentrations of 4-AP target a member of the $\mathrm{K}_{\mathrm{v}} 1$ family of $\mathrm{K}^{+}$channels. A higher concentrations 4-AP blocks a wide range of $\mathrm{K}^{+}$channels and is a potent proconvulsant. Thus, selective blockers of $\mathrm{K}_{\mathrm{v}} 1$ channels (and pending further confirmation with more specific channel blockers particularly the $\mathrm{K}_{\mathrm{v}} 1.5$ subfamily) may constitute safer and more effective candidates for treatment of EA2 and perhaps other cerebellar ataxia.

\section{References}

Alvina K, Khodakhah K (2008) Selective regulation of spontaneous activity of neurons of the deep cerebellar nuclei by N-type calcium channels in juvenile rats. J Physiol 586:2523-2538.

Alviña K, Khodakhah K (2010) $\mathrm{K}_{\mathrm{Ca}}$ channels as therapeutic targets in episodic ataxia type-2. J Neurosci 30:7249-7257.

Barclay J, Balaguero N, Mione M, Ackerman SL, Letts VA, Brodbeck J, Canti C, Meir A, Page KM, Kusumi K, Perez-Reyes E, Lander ES, Frankel WN, Gardiner RM, Dolphin AC, Rees M (2001) Ducky mouse phenotype of epilepsy and ataxia is associated with mutations in the Cacna2d2 gene and decreased calcium channel current in cerebellar Purkinje cells. J Neurosci 21:6095-6104.

Bever CT Jr, Young D, Anderson PA, Krumholz A, Conway K, Leslie J, Eddington N, Plaisance KI, Panitch HS, Dhib-Jalbut S (1994) The effects of 4-aminopyridine in multiple sclerosis patients: results of a randomized, placebo-controlled, double-blind, concentration-controlled, crossover trial. Neurology 44:1054-1059.

Buckle PJ, Haas HL (1982) Enhancement of synaptic transmission by 4-aminopyridine in hippocampal slices of the rat. J Physiol 326:109-122.

Campbell DB, North JB, Hess EJ (1999) Tottering mouse motor dysfunction is abolished on the Purkinje cell degeneration (pcd) mutant background. Exp Neurol 160:268-278.

Cao Y, Dreixler JC, Roizen JD, Roberts MT, Houamed KM (2001) Modulation of recombinant small-conductance $\mathrm{Ca}(2+)$-activated $\mathrm{K}(+)$ channels by the muscle relaxant chlorzoxazone and structurally related compounds. J Pharmacol Exp Ther 296:683-689.

Capacio BR, Byers CE, Matthews RL, Chang FC (1996) A method for determining 4-aminopyridine in plasma: pharmacokinetics in anaesthetized guinea pigs after intravenous administration. Biomed Chromatogr 10:111-116.

Chadderton P, Margrie TW, Hausser M (2004) Integration of quanta in cerebellar granule cells during sensory processing. Nature 428:856-860.

Chou R, Peterson K, Helfand M (2004) Comparative efficacy and safety of skeletal muscle relaxants for spasticity and musculoskeletal conditions: a systematic review. J Pain Symptom Manage 28:140-175.

Chung YH, Shin C, Kim MJ, Lee BK, Cha CI (2001) Immunohistochemical study on the distribution of six members of the Kvl channel subunits in the rat cerebellum. Brain Res 895:173-177.

Chung YH, Joo KM, Nam RH, Kim YS, Lee WB, Cha CI (2005) Immunohistochemical study on the distribution of the voltage-gated potassium channels in the gerbil cerebellum. Neurosci Lett 374:58-62.

Coetzee WA, Amarillo Y, Chiu J, Chow A, Lau D, McCormack T, Moreno H, Nadal MS, Ozaita A, Pountney D, Saganich M, Vega-Saenz dM, Rudy B (1999) Molecular diversity of K+ channels. Ann NY Acad Sci $868: 233-285$

Crawley JN (2008) Behavioral phenotyping strategies for mutant mice. Neuron 57:809-818.
Davies CH, Pozza MF, Collingridge GL (1993) CGP 55845A: a potent antagonist of $\mathrm{GABAB}$ receptors in the $\mathrm{CA1}$ region of rat hippocampus. Neuropharmacology 32:1071-1073.

Dove LS, Abbott LC, Griffith WH (1998) Whole-cell and single-channel analysis of P-type calcium currents in cerebellar Purkinje cells of leaner mutant mice. J Neurosci 18:7687-7699.

Etzion Y, Grossman Y (2001) Highly 4-aminopyridine sensitive delayed rectifier current modulates the excitability of guinea pig cerebellar Purkinje cells. Exp Brain Res 139:419-425.

Evans RM, Zamponi GW (2006) Presynaptic Ca2+ channels—integration centers for neuronal signaling pathways. Trends Neurosci 29:617-624.

Fletcher CF, Lutz CM, O'Sullivan TN, Shaughnessy JD Jr, Hawkes R, Frankel WN, Copeland NG, Jenkins NA (1996) Absence epilepsy in tottering mutant mice is associated with calcium channel defects. Cell 87:607-617.

Foster KA, Kreitzer AC, Regehr WG (2002) Interaction of postsynaptic receptor saturation with presynaptic mechanisms produces a reliable synapse. Neuron 36:1115-1126.

Friedman JH, Hollmann PA (1987) Acetazolamide responsive hereditary paroxysmal ataxia. Mov Disord 2:67-72.

Fureman BE, Jinnah HA, Hess EJ (2002) Triggers of paroxysmal dyskinesia in the calcium channel mouse mutant tottering. Pharmacol Biochem Behav 73:631-637.

Glasauer S, Kalla R, Buttner U, Strupp M, Brandt T (2005) 4-aminopyridine restores visual ocular motor function in upbeat nystagmus. J Neurol Neurosurg Psychiatry 76:451-453.

Grusser-Cornehls U, Baurle J (2001) Mutant mice as a model for cerebellar ataxia. Prog Neurobiol 63:489-540.

Harno H, Hirvonen T, Kaunisto MA, Aalto H, Levo H, Isotalo E, Somer H, Kallela M, Palotie A, Wessman M, Farkkila M (2004) Acetazolamide improves neurotological abnormalities in a family with episodic ataxia type 2 (EA-2). J Neurol 251:232-234.

Hausser M, Clark BA (1997) Tonic synaptic inhibition modulates neuronal output pattern and spatiotemporal synaptic integration. Neuron 19:665-678.

Hayes KC, Katz MA, Devane JG, Hsieh JT, Wolfe DL, Potter PJ, Blight AR (2003) Pharmacokinetics of an immediate-release oral formulation of Fampridine (4-aminopyridine) in normal subjects and patients with spinal cord injury. J Clin Pharmacol 43:379-385.

Hoebeek FE, Stahl JS, van Alphen AM, Schonewille M, Luo C, Rutteman M, van den Maagdenberg AM, Molenaar PC, Goossens HH, Frens MA, De Zeeuw CI (2005) Increased noise level of Purkinje cell activities minimizes impact of their modulation during sensorimotor control. Neuron 45:953-965.

Hoebeek FE, Khosrovani S, Witter L, De Zeeuw CI (2008) Purkinje cell input to cerebellar nuclei in tottering: ultrastructure and physiology. Cerebellum 7:547-558.

Hurlock EC, McMahon A, Joho RH (2008) Purkinje-cell-restricted restoration of Kv3.3 function restores complex spikes and rescues motor coordination in Kcnc3 mutants. J Neurosci 28:4640-4648.

Jen J, Kim GW, Baloh RW (2004) Clinical spectrum of episodic ataxia type 2. Neurology 62:17-22.

Jen JC, Graves TD, Hess EJ, Hanna MG, Griggs RC, Baloh RW (2007) Primary episodic ataxias: diagnosis, pathogenesis and treatment. Brain 130:2484-2493.

Jinnah HA, Hess EJ, LeDoux MS, Sharma N, Baxter MG, DeLong MR (2005) Rodent models for dystonia research: characteristics, evaluation, and utility. Mov Disord 20:283-292.

Judge SI, Bever CT Jr (2006) Potassium channel blockers in multiple sclerosis: neuronal $\mathrm{Kv}$ channels and effects of symptomatic treatment. Pharmacol Ther 111:224-259.

Judge SI, Lee JM, Bever CT Jr, Hoffman PM (2006) Voltage-gated potassium channels in multiple sclerosis: Overview and new implications for treatment of central nervous system inflammation and degeneration. J Rehabil Res Dev 43:111-122.

Kalla R, Glasauer S, Buttner U, Brandt T, Strupp M (2007) 4-aminopyridine restores vertical and horizontal neural integrator function in downbeat nystagmus. Brain 130:2441-2451.

Lagrutta A, Wang J, Fermini B, Salata JJ (2006) Novel, potent inhibitors of human $\mathrm{Kv} 1.5 \mathrm{~K}^{+}$channels and ultrarapidly activating delayed rectifier potassium current. J Pharmacol Exp Ther 317:1054-1063.

Llinas R, Sugimori M (1980) Electrophysiological properties of in vitro Purkinje cell dendrites in mammalian cerebellar slices. J Physiol 305:197-213. 
Lohle M, Schrempf W, Wolz M, Reichmann H, Storch A (2008) Potassium channel blocker 4-aminopyridine is effective in interictal cerebellar symptoms in episodic ataxia type 2-a video case report. Mov Disord 23:1314-1316.

Madeja M, Musshoff U, Speckmann EJ (1997) Diversity of potassium channels contributing to differences in brain area-specific seizure susceptibility: sensitivity of different potassium channels to the epileptogenic agent pentylenetetrazol. Eur J Neurosci 9:390-395.

Maren TH (1967) Carbonic anhydrase: chemistry, physiology, and inhibition. Physiol Rev 47:595-781.

Martina M, Yao GL, Bean BP (2003) Properties and functional role of voltage-dependent potassium channels in dendrites of rat cerebellar Purkinje neurons. J Neurosci 23:5698-5707.

Matsushita K, Wakamori M, Rhyu IJ, Arii T, Oda S, Mori Y, Imoto K (2002) Bidirectional alterations in cerebellar synaptic transmission of tottering and rolling Ca2 + channel mutant mice. J Neurosci 22:4388-4398.

Mori Y, Friedrich T, Kim MS, Mikami A, Nakai J, Ruth P, Bosse E, Hofmann F, Flockerzi V, Furuichi T (1991) Primary structure and functional expression from complementary DNA of a brain calcium channel. Nature 350:398-402.

Ophoff RA, Terwindt GM, Vergouwe MN, van Eijk R, Oefner PJ, Hoffman SM, Lamerdin JE, Mohrenweiser HW, Bulman DE, Ferrari M, Haan J, Lindhout D, van Ommen GJ, Hofker MH, Ferrari MD, Frants RR (1996) Familial hemiplegic migraine and episodic ataxia type- 2 are caused by mutations in the Ca2 + channel gene CACNL1A4. Cell 87:543-552.

Otis TS, Jen JC (2006) Blessed are the pacemakers. Nat Neurosci 9:297-298.

Ovsepian SV, Friel DD (2008) The leaner P/Q-type calcium channel mutation renders cerebellar Purkinje neurons hyper-excitable and eliminates $\mathrm{Ca} 2+-\mathrm{Na}+$ spike bursts. Eur J Neurosci 27:93-103.

Pietrobon D (2005) Function and dysfunction of synaptic calcium channels: insights from mouse models. Curr Opin Neurobiol 15:257-265.

Raman IM, Bean BP (1999) Ionic currents underlying spontaneous action potentials in isolated cerebellar Purkinje neurons. J Neurosci 19:16631674 .

Sacco T, Tempia F (2002) A-type potassium currents active at subthreshold potentials in mouse cerebellar Purkinje cells. J Physiol 543:505-520.

Shirley TL, Rao LM, Hess EJ, Jinnah HA (2008) Paroxysmal dyskinesias in mice. Mov Disord 23:259-264.

Stea A, Tomlinson WJ, Soong TW, Bourinet E, Dubel SJ, Vincent SR, Snutch TP (1994) Localization and functional properties of a rat brain alpha $1 \mathrm{~A}$ calcium channel reflect similarities to neuronal Q- and P-type channels. Proc Natl Acad Sci U S A 91:10576-10580.

Stone TW (1993) Neuropharmacology of quinolinic and kynurenic acids. Pharmacol Rev 45:309-379.

Strupp M, Brandt T (2006) Pharmacological advances in the treatment of neuro-otological and eye movement disorders. Curr Opin Neurol 19:33-40.

Strupp M, Kalla R, Dichgans M, Freilinger T, Glasauer S, Brandt T (2004) Treatment of episodic ataxia type 2 with the potassium channel blocker 4-aminopyridine. Neurology 62:1623-1625.

Strupp M, Kalla R, Freilinger T, Dichgans M, Brandt T (2005) Dysfunction of the brain calcium channel CaV2.1 in absence epilepsy and episodic ataxia-a comment. Brain 128:E32.

Strupp M, Zwergal A, Brandt T (2007) Episodic ataxia type 2. Neurotherapeutics 4:267-273.

Strupp M, Kalla R, Glasauer S, Wagner J, Hufner K, Jahn K, Brandt T (2008) Aminopyridines for the treatment of cerebellar and ocular motor disorders. Prog Brain Res 171:535-541.

Syme CA, Gerlach AC, Singh AK, Devor DC (2000) Pharmacological activation of cloned intermediate- and small-conductance $\mathrm{Ca}(2+)$-activated $\mathrm{K}(+)$ channels. Am J Physiol Cell Physiol 278:C570-C581.

Usowicz MM, Sugimori M, Cherksey B, Llinas R (1992) P-type calcium channels in the somata and dendrites of adult cerebellar Purkinje cells. Neuron 9:1185-1199.

Walter JT, Khodakhah K (2006) The linear computational algorithm of cerebellar Purkinje cells. J Neurosci 26:12861-12872.

Walter JT, Alvina K, Womack MD, Chevez C, Khodakhah K (2006) Decreases in the precision of Purkinje cell pacemaking cause cerebellar dysfunction and ataxia. Nat Neurosci 9:389-397.

Wan J, Ernstgard L, Song BJ, Shoaf SE (2006) Chlorzoxazone metabolism is increased in fasted Sprague-Dawley rats. J Pharm Pharmacol 58:51-61.

Weisz CJ, Raike RS, Soria-Jasso LE, Hess EJ (2005) Potassium channel blockers inhibit the triggers of attacks in the calcium channel mouse mutant tottering. J Neurosci 25:4141-4145.

Womack M, Khodakhah K (2002) Active contribution of dendrites to the tonic and trimodal patterns of activity in cerebellar purkinje neurons. J Neurosci 22:10603-10612.

Womack MD, Khodakhah K (2003) Somatic and dendritic smallconductance calcium-activated potassium channels regulate the output of cerebellar purkinje neurons. J Neurosci 23:2600-2607.

Womack MD, Khodakhah K (2004) Dendritic control of spontaneous bursting in cerebellar Purkinje cells. J Neurosci 24:3511-3521.

Womack MD, Chevez C, Khodakhah K (2004) Calcium-activated potassium channels are selectively coupled to $\mathrm{P} / \mathrm{Q}$-type calcium channels in cerebellar Purkinje neurons. J Neurosci 24:8818-8822.

Yoon KW, Covey DF, Rothman SM (1993) Multiple mechanisms of picrotoxin block of GABA-induced currents in rat hippocampal neurons. J Physiol 464:423-439.

Zasorin NL, Baloh RW, Myers LB (1983) Acetazolamide-responsive episodic ataxia syndrome. Neurology 33:1212-1214. 